\title{
Characteristics of the preschool home literacy environment which predict writing skills at school
}

\author{
Anne-Marie Adams ${ }^{1}\left[\right.$ [ . Elena Soto-Calvo ${ }^{1} \cdot$ Hannah N. Francis ${ }^{1}$. \\ Hannah Patel ${ }^{1}$. Courtney Hartley ${ }^{1}$. David Giofrè ${ }^{2} \cdot$ Fiona R. Simmons ${ }^{1}$
}

Accepted: 29 January 2021 / Published online: 18 March 2021

(c) The Author(s) 2021

\begin{abstract}
Aspects of the preschool home learning environment which may foster reading development have been identified, although their relationships with spelling and writing remain unclear. The present study explored associations between the preschool home literacy environment (HLE), language and nonverbal abilities and children's spelling and writing skills measured two years later. A parental questionnaire recorded the reported frequency of pre-schoolers' code- and meaning-related home literacy experiences, alongside an index of book exposure. One hundred and twenty one children (60 female, $M_{\text {age }}=6: 7, \mathrm{SD}=3.67$ months) contributed data assessing their transcription skills, indexed by handwriting fluency and word spelling, and translation abilities, indexed by sentence generation and the ability to produce more extended text. Exploratory factor analyses confirmed distinct factors relating to the productivity and complexity of writing samples. Regression analyses revealed that the frequency of preschool code-related, letter-sound interactions explained significant variance in children's transcription skills at school, independently of earlier language and nonverbal abilities. In contrast, experiences in the preschool HLE were not related to the higher level writing skills of translation and text production. The implications of the findings for our understanding of the cognitive and environmental factors associated with children's early writing development are discussed.
\end{abstract}

Keywords Preschool $\cdot$ Home literacy environment $\cdot$ Spelling $\cdot$ Writing

Part of the work was conducted whilst the author was at the School of Psychology, Liverpool John Moores University.

Anne-Marie Adams

a.adams@ljmu.ac.uk

Fiona R. Simmons

F.R.Simmons@ljmu.ac.uk

1 School of Psychology, Liverpool John Moores University, Liverpool, UK

2 Department of Educational Sciences, University of Genoa, Genova, Italy 


\section{The home literacy environment and reading}

The preschool home environment includes many valuable and enjoyable opportunities for learning about literacy, potentially benefitting children's readiness to engage with the literacy curriculum (Niklas \& Schneider, 2017) and future literacy development (de Jong \& Leseman, 2001). Critically, the preschool home literacy environment (HLE) encompasses a wide array of experiences with different experiences supporting the development of distinct literacy skills (see Sénéchal et al., 2017 for an overview).

The task of capturing accurately the nature of the HLE is challenging, with issues related to terminology and methodology persisting. Studies have variously distinguished preschool experiences as formal or informal (Sénéchal \& LeFevre, 2002), 'inside out' or 'outside in' (Whitehurst \& Lonigan, 1998) and parental teaching or shared reading (Hood et al., 2008). Acknowledging the need for greater clarity and conformity in terminology, a recent review (Sénéchal et al., 2017) favoured the categorisation of code- and meaning-related experiences. Meaning-related experiences encompass activities focusing on the meaning of oral or written language, with the archetypal meaning-related experience being shared reading. Experiences categorised as code-related focus on the orthographic and phonological features of language. Drawing a child's attention to the initial letter of their name in print, perhaps also noting its sound, is an example of such an activity. Sénéchal and colleagues suggest that experiences categorised in this way bear differential relationships with the development of reading and reading-related skills. To summarise, code-related experiences appear more closely connected to the development of skills important in word decoding, whereas meaning-related experiences appear not to be directly related to this skill, although they may bear an indirect association with reading comprehension through oral language skills (e.g., Hamilton et al., 2016; Hood et al., 2008; Manolitsis et al., 2013; Martini \& Sénéchal, 2012; Sénéchal, 2006; Skwarchuk et al., 2014). However, not all the salient characteristics of the HLE may be adequately captured by this simple distinction. Krijnen et al. (2020) argued that experiences within the HLE might be distinguishable along two independent axes; one reflecting the code and meaning distinction and another reflecting the manner of engagement varying from playful exposure to direct teaching. Exploratory factor analysis fractionated meaning-related activities into two distinct factors: (1) those representing activities with a direct teaching element, and (2) those including activities focused around playful exposure. Code-related activities did not though fractionate into separate teaching and exposure subscales.

\section{Spelling and writing}

The body of work exploring the development of reading skills dwarfs that relating to the development of spelling and writing skills. Nevertheless, important strides are being made towards understanding the trajectory of spelling and writing development and factors which underpin individual differences in their 
mastery (Kent et al., 2014; Kim et al., 2011; Treiman et al., 2019; Wagner et al., 2011). Building upon the simple view of reading (Gough \& Tunmer, 1986) which acknowledged the decoding and comprehension aspects of reading, the simple view of writing (Juel, 1988) highlighted the need to master both the mechanics and the communicative aspects of writing. Its later formulation, as the 'not-sosimple' view of writing (Berninger \& Winn, 2006), included roles for working memory and executive function resources in written text composition.

Processes underpinning skilled writing encompass planning (i.e., the generation of ideas and the organisation of the text) to achieve its communicative function, translating (i.e., transforming these ideas into sentences) and revising, (i.e., evaluating the writing against its communicative goals). However, the primary challenge for beginning writers is proposed to be translation, as they wrestle with the demands of producing letters, spelling words and combining these into syntactically appropriate sentences (Kim et al., 2011). To reflect this, models of early writing (e.g. Berninger et al., 1992) further divide the translation process into text generation (i.e., the encoding of ideas into words, phrases and sentences) and transcription (i.e., spelling and handwriting skills). The predictions of the not-so-simple view of writing, in which text generation, transcription, oral language and executive function interact to produce text within the constraints of the individual's working memory capacity, have been supported in the literature (e.g., Drijbooms et al., 2015; Olinghouse \& Leaird, 2008; Salas \& Silvente, 2020).

Typically, the operation of these processes is assessed through their impact on the writing product and measured at the microstructural (i.e., word and sentence) and macrostructural (i.e., global text) levels, capturing features of both productivity and complexity (Arfé et al., 2016; Kim et al., 2015; Wagner et al., 2011). At the word level, the number of words produced and the percentage of words spelled accurately is measured, whilst at the sentence level the combination of words in clauses and sentences is assessed. In beginning writers, who typically engage in little planning, the number of ideas is often used to index the macrostructural properties of texts. The distinction between indices which reflect text productivity and those which reflect its complexity has been reliably identified and each has been shown to capture variation in children's writing performance (Mackie et al., 2013; Puranik et al., 2008). Moreover, there is evidence indicating differential associations between cognitive skills and writing measured at the word, sentence and text levels (Drijbooms et al., 2015; Salas \& Silvente, 2020). This evidence emphasises the need to undertake comprehensive assessments of the writing performance of young children to develop an accurate picture of writing development and the factors which may impact upon its success. 


\section{Home literacy environment and spelling and writing}

Relationships between the HLE and spelling and writing have been investigated previously, however, key questions remain. Some studies have amalgamated multiple aspects of spelling and writing within a single index of literacy development and thus particular relationships between the HLE and specific components of writing are not evaluated (Puglisi et al., 2017; Sénéchal et al., 1998). Other studies have explored the relationship between the HLE and the very specific skill of writing one's own name (Gerde et al., 2012; Weigel et al., 2006). However, despite its close association with emergent literacy skills (Puranik \& Lonigan, 2012), name writing may be a somewhat idiosyncratic index of writing development (Drouin \& Harmon, 2009). There is thus a need to systematically evaluate associations between the HLE and specific writing processes appropriate to beginning writers.

The relationship between the HLE and spelling individual words has been investigated in beginning writers. Findings converge with those from reading to indicate that code-related experiences, rather than meaning-related activities such as shared reading, may be particularly salient in the development of alphabetic knowledge that underpins the development of spelling skills (Hood et al., 2008).

Very few studies have investigated relationships between the HLE and writing beyond the single word level in early writers (Guo et al., 2020; Hofslundsengen et al., 2019; Puranik et al., 2018). Puranik et al. (2018) explored home practices related directly to writing, conceptualised as parental teaching or child-independent practices. They demonstrated that the incorporation of fundamental features of early writing (e.g., linearity and conventional symbol use), was related to the frequency of parent-child interactions around writing with a specific didactic focus. Similarly, Hofslundsengen et al. (2019) evaluated the extent to which young children's writing approximated phonologically or orthographically accurate renditions of a dictated sentence. Their composite measure of the HLE, comprising a rating of parental modelling of literacy activities and a single item reporting the frequency of shared reading, was not directly related to writing ability, although there were significant indirect associations through vocabulary and phonological awareness.

Both the studies described above, likely necessitated by the children's limited writing abilities, applied an overall scale rating key features of emergent writing, rather than indices directly related to specific writing processes. Guo et al. (2020) did address this issue, measuring writing at the sub-lexical (letter writing), lexical, sentential and text levels, in the first year of school. Only the frequency of children's independent reading and writing at home predicted contemporaneously assessed writing abilities, with instances of children's independent reading also predicting spelling abilities six months later. The frequency of shared reading, parental teaching of reading or activities to support children's writing were not related to writing performance. This lack of association between writing performance and the frequency of parental support of writing activities was unexpected given previous evidence of its facilitative role in writing development (Aram et al., 2013). Similarly, since parental teaching of reading has been shown to be related to the development of code-related knowledge (e.g., Sénéchal \& LeFevre, 2002; Stephenson et al., 
2008), the absence of an association between children's writing and parental teaching of reading was difficult to explain, given the significant code-related features of spelling and writing (Adams et al., 2015; Puranik \& Lonigan, 2012). However, Guo and colleagues assessed the HLE by asking parents to rate the frequency with which they taught their children about letters and words whilst reading books only. We extend this work by applying code- and meaning-related scales that index a wider range of preschool home literacy experiences.

\section{The present study}

The aim of the present study was to determine the extent to which preschool codeand meaning-related home literacy experiences predict spelling and writing skills once a child has commenced primary education. The following research questions relating to the time period of the HLE, the nature of HLE experiences and certain characteristics of writing, extended previous evidence.

1. Does the preschool HLE predict later spelling and writing skills?

Differential relationships have been identified between reading and the HLE dependent upon when the home environment is assessed, with weaker relationships observed when the HLE is assessed after schooling has begun (Inoue et al., 2018; Krijnen et al., 2020). Whilst previous studies have evaluated contemporaneous associations between spelling and writing and the preschool HLE (Hofslundsengen et al., 2019; Puranik et al., 2018), or longitudinal associations with the school HLE (Guo et al., 2020), the present study will explore relationships between school writing and the earlier preschool HLE. We hypothesised that the preschool HLE would predict significant variance in children's writing performance at school.

2. Do code- and meaning-related HLE experiences bear differential relationships with spelling and writing?

We assessed both meaning- and code-related experiences with a range of items reflecting both teaching-focused interactions and playful exposure. Additionally, we indexed shared reading using a book exposure checklist. Our measures reflect the theoretically valuable code- and meaning- distinction derived from reading research (Sénéchal et al., 2017). We hypothesised that code-related experiences would bear closer relationships with spelling and writing than those based around meaning.

3. Does the HLE predict word, sentence and text level writing?

Our measures of writing span sub-lexical, lexical, sentential and textual aspects incorporating, where appropriate, indices of productivity and complexity reflecting specific writing processes (Berninger \& Winn, 2006). The home literacy model (Sénéchal, 2006; Sénéchal \& LeFevre, 2002), alongside evidence of differential associations between code-related experiences and word reading and between meaning-related experiences and reading comprehension (Hamilton et al., 2016; Hood et al., 2008; Manolitsis et al., 2013) guided our predictions. We hypothesised associations between code-related experiences and sub-lexical 
and lexical writing and between meaning-related and sentence and text level writing.

4. Are any relationships between the preschool HLE and later writing independent of children's language ability and cognitive skills?

Given the close relationships observed between oral language and cognitive, particularly executive function, skills (Dockrell et al., 2019; Drijbooms et al., 2015; Olinghouse \& Leaird, 2008; Salas \& Silvente, 2020), we examined the more stringent test of unique associations between HLE and writing; relationships which are independent of these abilities. Previous research has controlled for one of these factors (Hofslungsengen et al., 2018; Puranik et al., 2018), but not both. Based on the evidence from reading (see Sénéchal et al., 2017), we predicted that code- but not meaning-related experiences would share unique variance with writing.

\section{Method}

\section{Design}

The data reported here forms part of a broader study investigating relationships between preschool cognitive and environmental factors and later academic attainment. A parental survey, completed in the spring term of their child's final preschool year $\left(\mathrm{T}_{1}\right)$ indexed the HLE. Children completed language and cognitive assessments at their preschool setting in the summer term of their final pre-school year $\left(\mathrm{T}_{2}\right)$. Children's spelling and writing was assessed at their school in the first term of their second school year $\left(\mathrm{T}_{3}\right)$. Correlational analyses and hierarchical regressions evaluate associations between preschool environmental and cognitive factors and school productive literacy.

\section{Participants}

The current sample consisted of 121 parent-child dyads (115 female parents, 83 female children) participating in a wider longitudinal study examining the impact of the home learning environment on different aspects of academic attainment (see Soto-Calvo et al., 2020a, b). Parental report stated that $9.1 \%$ of this sample $(n=11)$ spoke a language in addition to English in the home, 3.3\% $(n=4)$ were described as having or undergoing investigation for a special educational need or disability. Since these children were judged able to comprehend the task instructions and responded appropriately during practice trials and given that including these children in the sample provides a more accurate reflection of the population of children attending mainstream education in the UK than excluding them, all children who contributed writing data were included in the current sample,

At $\mathrm{T}_{1}$ all parents gave written consent for their child $\left(M_{\text {age }}=3: 11\right.$ years, $S D=3.6$ months) to participate in the study and were requested to complete a home experiences questionnaire. Data were available for 117 children from the current sample. The deprivation levels of the children's home postcode, according to the 
2015 index of multiple deprivation (accessed from http://imd-by-postcode.opend atacommunities.org/), provided an index of socio-economic status. Indices of parental educational attainment were derived from their highest qualification coded according to the National Qualification Framework (https://www.gov.uk/what-diffe rent-qualification-levels-mean/list-of-qualification-levels). This scale levels qualifications from 1 (qualifications equivalent to a lower grade GCSE) to 8 (doctoral level qualifications). Descriptive statistics of postcode deprivation and parental qualification available for children in the current sample are presented in Table 1. At $\mathrm{T}_{2}$ (the final term of their preschool year) 115 of these children (58 female, $M_{\text {age }}=4: 3$, $\mathrm{SD}=3.73$ months) completed language and cognitive assessments. Trained researchers administered these tasks individually to each child in their preschool setting, in a fixed order across three assessment sessions. At $\mathrm{T}_{3}, 121$ children (60 female, $M_{\text {age }}=6: 7 \mathrm{SD}=3.67$ months) completed the spelling and writing tasks. The second author administered the tasks in a fixed order individually to each child in a single session within their school setting.

\section{Measures}

\section{The home learning environment questionnaire}

Home literacy experiences $\left(T_{1}\right)$ The questionnaire asked parents to report the frequency, on a 6-point Likert scale ranging from never (0) to several times a day (5), their child experienced, at home, each of 32 activities. Activities represented eight

Table 1 Descriptive statistics for the socio-economic indices, HLE scales, language and nonverbal measures

\begin{tabular}{lllrll}
\hline & $\mathrm{N}$ & Mean & SD & Range & $\alpha$ \\
\hline Postcode deprivation & 116 & 5.77 & 3.16 & $1-10$ & \\
Parental qualification & 117 & 4.94 & 1.91 & $0-8$ & \\
Book exposure & 115 & 52.75 & 22.45 & $0-100$ & \\
Code-related: letter activities & 117 & -.06 & 0.93 & $-2.30-1.99$ & \\
Code-related: letter-sound interactions & 117 & 0.01 & 0.95 & $-2.62-1.54$ & \\
Meaning-related experiences & 117 & -.06 & 0.93 & $-2.67-1.70$ & \\
Rhyme awareness & 112 & -10.11 & 2.81 & $5-17$ & $.83^{\mathrm{a}}$ \\
Alliteration awareness & 114 & 10.25 & 3.06 & $6-17$ & $.84^{\mathrm{a}}$ \\
Naming vocabulary & 115 & 52.78 & 9.87 & $29-80$ & $.73^{\mathrm{a}}$ \\
Receptive vocabulary & 109 & 9.85 & 3.14 & $2-18$ & $.89^{\mathrm{a}}$ \\
Matrices & 115 & 42.77 & 8.70 & $24-65$ & $.75^{\mathrm{a}}$ \\
Picture similarities & 113 & 45.65 & 9.30 & $30-80$ & $.79^{\mathrm{a}}$ \\
Big/Little Stroop & 111 & 72.75 & 29.15 & $0-100$ & $.77^{\mathrm{b}}$ \\
Fish/Shark d' & 106 & 1.83 & 1.11 & $-.85-3.77$ & - \\
\hline
\end{tabular}

${ }^{a}$ Inter-item reliability of the standardisation sample. ${ }^{\mathrm{b}}$ Inter-item reliability of older preschool sample (Kochanska et al. 2000) 
number-related experiences, eight meaning- and seven code-related literacy experiences. Items were randomly ordered within the questionnaire, interspersed with nine filler items (e.g., 'rides a scooter, balance bike or bike'). Only items relating to home literacy experiences are considered in the current study. The reliability and coherence of the code- and meaning-related subscales were appraised using exploratory factor analysis in a sample of 274 parent-preschool child dyads (254 female parents, 146 female children, child $M_{\text {age }}=3: 11$ years, $\mathrm{SD}=3.6$ months, including 117 children from the current study) which has been reported previously (Soto-Calvo et al., 2020a). Six items loaded onto a single meaning-related factor. The code-related items loaded onto two distinct factors; three items were characterised as children's activities centred around letters, hereafter termed letter activities, and four items characterised as relating to parent-child interactions around letters and their sounds, hereafter termed letter-sound interactions. Table 2 presents the survey items comprising the scales of code-related letter activities, code-related letter-sound interactions and meaningrelated experiences, alongside each item's factor loading on their respective scale, and the scale reliability. A child's factor score on the relevant scale is used to index home literacy experiences. Descriptive statistics for these indices are provided in Table 1.

Parental report of book exposure $\left(T_{1}\right)$ The book exposure index was based on previous measures (Hamilton et al., 2016; Puglisi et al., 2017), modified for applicability to the parents of English pre-schoolers at the time of testing. The titles of 21 potential preschool books were presented to parents. They were asked to indicate for each title whether they believed it to be 'real', 'made up' or to respond 'don't know'. Fifteen of the titles were the titles of real books with the remaining six titles being foils, plausible titles invented by the authors (see Soto-Calvo et al., 2020a for a full list of titles). Instructions encouraged parents to refrain from guessing. However, to limit any residual influence of guessing, in accordance with a similar index reported by Skwarchuk et al. (2014) the formula [(Real titles identified as real-Foil titles identified as real)/total number of titles $\times 100$ ] was applied and reported (see Table 1 for the descriptive statistics).

\section{Child language assessments $\left(\mathrm{T}_{2}\right)$}

Phonological awareness was assessed using two subtests from the Preschool and Primary Inventory of Phonological Awareness (Dodd et al., 2000). Alliteration Awareness required the child to identify the word from a set of four that started with a different sound. Rhyme Awareness required the child to identify which word from a set of four did not rhyme with the other words. Each task comprised 12 test items preceded by two practice items. Children's vocabulary was assessed using two standardised measures. The first was the Naming Vocabulary subtest taken from the British Ability Scales III (Elliott \& Smith, 2011) in which the child is asked to name pictures presented to them. The Receptive Vocabulary subtest taken from the Wechsler Preschool and Primary Scale of IntelligenceFourth UK Edition (Wechsler, 2013) asked each child to point to the picture, from a choice of four, which best matched the word spoken by the researcher. 


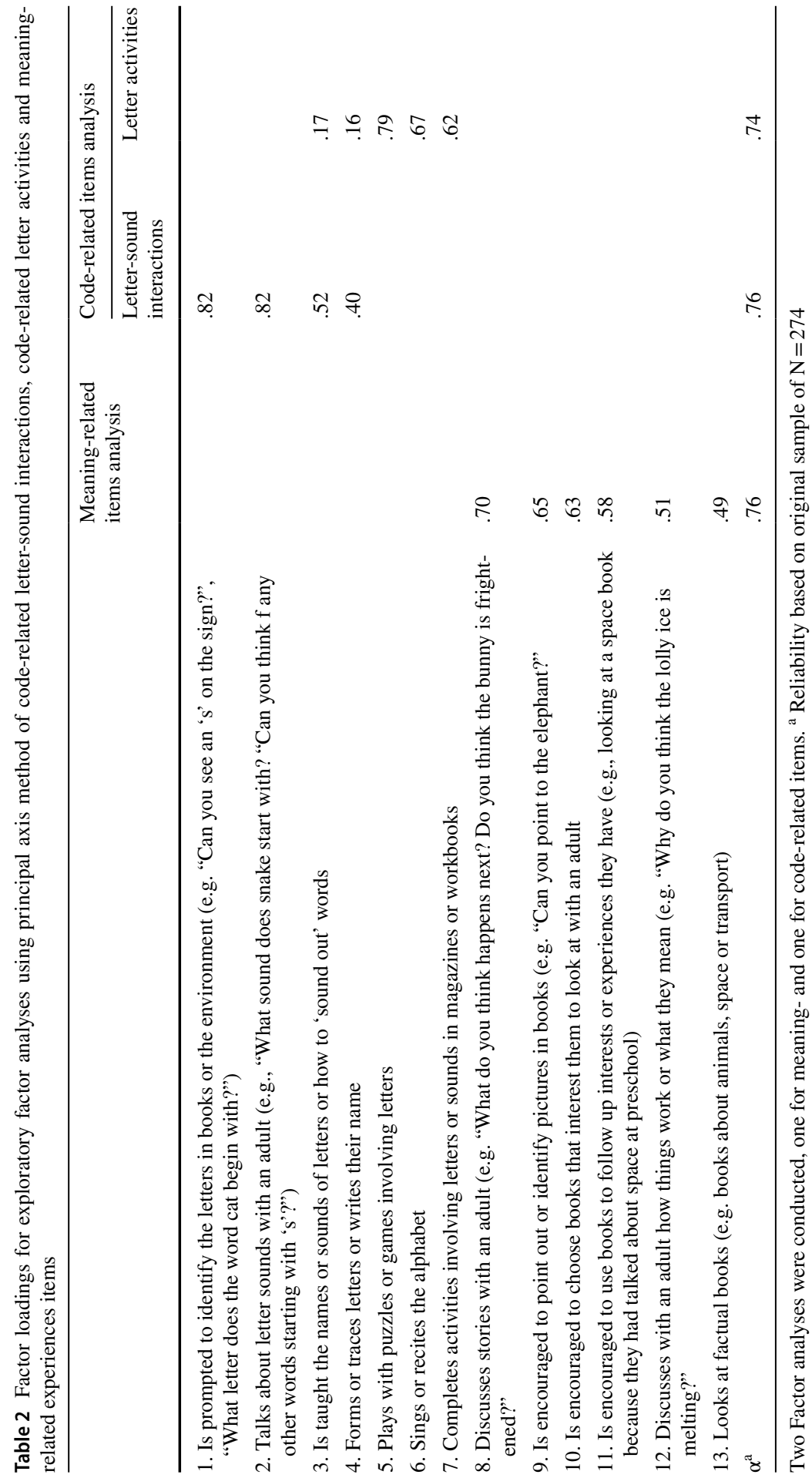




\section{Child cognitive assessments $\left(T_{2}\right)$}

Inhibitory control (IC) was assessed using two computerised tasks. In the Fish/ Shark task (Wiebe et al., 2012) children were asked to press a key when they saw a picture of a fish (75\% of trials) but to inhibit this response when the picture showed a shark (25\% of trials). The $d$ ' index, calculated by subtracting the $z$-score value of the hit rate right-tail $p$ value from the $z$-score value of the false alarm rate right-tail $p$ value was reported. This sensitivity index represents the accuracy with which the child detects fishes and rejects sharks. In the Big/Little Stroop task (modified from Kochanska et al., 2000) each child was presented with a large outline of an animal appearing first for $750 \mathrm{~ms}$, followed by the presentation of smaller animal outlines within this outline. The child was required to name the smaller animals contained within the larger animal outline. Trials were split equally between congruent trials (where animals depicted in the smaller and larger outlines matched) and incongruent trials (where animals depicted in the smaller and larger outlines differed). The number of correct responses to the incongruent trials was reported. Both IC tasks have been shown to capture variance within the age range of our sample (Kochanska et al., 2000; Wiebe et al., 2012). Two standardised tests from the British Ability Scales III indexed nonverbal reasoning (Elliot \& Smith, 2011). In the Matrices subtest the children were shown an incomplete grid of shapes and asked to select one shape from a choice of four that best completed the pattern. In the Picture Similarities subtest each child is shown a set of four pictures and then given a card to match to the picture with which it shares a link.

Composite measures of language and nonverbal abilities were constructed on the basis of the results of Confirmatory Factor Analyses (CFA, for further details see Soto-Calvo et al., 2020b). This CFA was conducted with a larger sample of 265 preschool children $\left(M_{\text {age }}=4: 3 \mathrm{SD}=3.67\right.$ months), which included 103 children from the current study who had complete language and nonverbal data. It confirmed that the best fitting model consisted of two factors, language and nonverbal ability. Therefore, the Language composite comprised the mean of the $z$-scores for Alliteration awareness, Rhyme awareness, Receptive vocabulary and Naming vocabulary. The nonverbal ability composite comprised the mean of the $z$-scores of Matrices, Picture similarities, Big/Little Stroop and Fish/Shark d'. A composite language score and composite nonverbal score were calculated for all children with full data for the set of contributing variables. These composite indices align with similar methodologies in previous HLE research (Hamilton et al., 2016; Manolitsis et al., 2013). Descriptive statistics for the individual measures of language and nonverbal abilities are provided in Table 2.

\section{Spelling and writing $\left(\mathrm{T}_{3}\right)$}

To evaluate scoring reliability, the first author scored all the measures with a random selection of $20 \%$ of the participants' also independently scored by the last named author, blind to the initial assessment. Inter-rater reliability was calculated using 
Table 3 Descriptive statistics for the spelling and writing measures

\begin{tabular}{llll}
\hline & $N$ & Mean & SD \\
\hline Alphabet transcription & 121 & 4.78 & 2.64 \\
BAS spelling $^{\text {a }}$ & 121 & 105.84 & 14.04 \\
SG. total score & 120 & 7.72 & 4.10 \\
SG. number of words & 120 & 33.45 & 14.42 \\
SG. \% spelled correct & 120 & .86 & .14 \\
SG. number of T-units & 120 & 5.01 & 2.27 \\
SG. MLT-units & 118 & 6.77 & 2.20 \\
SG. number of clauses & 120 & 5.22 & 2.46 \\
SG. clause density & 118 & 1.04 & 0.11 \\
TP. number of ideas & 121 & 7.94 & 2.86 \\
TP. number of words & 121 & 24.18 & 12.75 \\
TP. \% spelled correct & 121 & .71 & .25 \\
TP. number of T-units & 121 & 2.31 & 2.39 \\
TP. MLT-units & 74 & 7.61 & 2.85 \\
TP. number of clauses & 121 & 3.05 & 3.16 \\
TP. clause density & 74 & 1.40 & 0.52 \\
\hline
\end{tabular}

SG, Sentence Generation; TP, Text Production; MLT-units, Mean Length of T-units

${ }^{a}$ Age-standardised score. The writing tasks were presented to all 121 participants. One child did not engage with the sentence generation task. Clause density and mean length of T-units were calculated only for participants who produced at least one clause or T-unit respectively

intraclass correlations (ICC) based on absolute agreement between the two raters. Descriptive statistics for the spelling and writing measures can be found in Table 3 .

\section{Alphabet transcription}

This task, assessing the fluency of transcription processes at the sub-lexical level, was based on the alphabet writing task from the Wechsler Individual Achievement Tests (Wechsler, 2005). Children were presented with lined paper on which the first letter of the alphabet was printed in lower case. They were asked to continue writing the letters of the alphabet, in sequence, for $15 \mathrm{~s}$. The number of letters produced was recorded. A more lenient scoring procedure than that advocated in the WIAT_II UK was applied. The strict formation guidelines were relaxed and raters credited each letter that was judged identifiable and could be distinguished from the other letters formed. For alphabet transcription ICC $=0.94, p<0.001$.

\section{Word spelling}

The children's ability to spell individual words to dictation was appraised using the British Ability Scales III (BAS-3, Elliot \& Smith, 2011). 


\section{Sentence generation}

This task reflects children's ability to generate ideas in written sentences and represents translation processes in writing at the sentence level (Arfé et al., 2016; Dockrell et al., 2019). In a practice trial, children were presented with a lined sheet of paper at the top of which was printed the word pair child-car. The experimenter explained that they wanted the child to play a game where they made up as many sentences as they could which included these two words. The experimenter spoke two such sentences aloud and modelled writing them. The children were then told it was their turn and they should try to write as many sentences as they could using the words man-dog. The children were encouraged to continue writing sentences for five minutes. Semantically and syntactically correct sentences that contained both targets were awarded 2 points. Sentences considered to be only minimally semantically or syntactically different from previous sentences, were awarded 1 point. Errors in punctuation, capitalisation or misspellings were ignored. The number of points awarded to each sentence was summed to provide the sentence generation total score for which $\mathrm{ICC}=0.98, p<0.001$.

Sentence generation productivity was assessed at the microstructural (i.e., word and sentence) level. At the word level the total number of words and the proportion of correctly spelled words were scored. At the sentence level, the total number of T-units and the total number of clauses were scored. T-units are syntactic units of meaning corresponding to a main clause and any subordinate clauses embedded within it (Hunt, 1965). Clauses that began with a coordinating conjunction (e.g., and, so) were considered to signal the start of a new T-unit. The microstructural complexity of the texts as an index of translation processes, reflecting the ability to combine words and phrases, was assessed through (i) the mean length of T-units (the total number of words divided by the number of T-Units), (ii) clause density, (the total number of clauses divided by the number of T-units). Higher scores represent greater complexity. Inter-rater reliability for the sentence generation measures ranged from $\mathrm{ICC}=0.62, p=0.011$ for clause density, to $\mathrm{ICC}=0.99, p<0.001$ for the total number of words.

\section{Text production}

To assess the ability to produce text beyond the sentence level, the children were asked to compose an extended text to the prompt "At school I like...". Each child was given two minutes before writing to discuss with the experimenter a set of four pictures showing children engaging in typical primary school activities (e.g., working in class and playing in the playground). They were then provided with a sheet of lined paper on which the prompt was printed and asked to write about the things they liked doing at school. They were encouraged to write for five minutes, after which time the task was stopped, though they were allowed to finish any sentence they had already started when the time elapsed.

The same measures of productivity and complexity adopted in sentence generation were applied to texts produced in response to the prompt. To assess productivity at the text (macrostructural) level, the number of ideas in each text was measured 
(e.g., Kim et al., 2011). A main proposition (i.e., predicate and argument) such as "I like school" was counted as a single idea, while each further embellishment such as "I like playtime at school" was counted as two ideas. This measure is proposed to reflect idea generation during writing and is traditionally incorporated within planning processes in models of writing (Hooper et al., 2002; Wagner et al., 2011). Reliability estimates for the texts generated in response to the prompt ranged from ICC $=94, p<0.001$ for clause density to $\mathrm{ICC}=0.99, p<0.001$ for the number of words.

\section{Results}

\section{Descriptive statistics}

Descriptive statistics for the socio-economic indices, HLE scales, language and cognitive abilities are presented in Table 1 and for the measures of spelling and writing in Table 3. Combined, these statistics render us confident that the sample is representative of the population of English children from which it was drawn. The sample's average postcode deprivation index places it very close to the population mean statistic (5, http://imd-by-postcode.opendatacommunities.org/) and the mean standard scores for the language and nonverbal ability measures are broadly consistent with the tests' standardisation samples.

\section{Components of children's writing}

In order to rationalise the number of measures, Exploratory Factor Analysis (EFA) initiated with Principal Components Analysis (to confirm the orthogonal status of the factors) subsequently applying the Varimax rotation with Kaiser normalisation, evaluated the factor structure of the microstructural measures derived from children's sentence and text production. The following variables were included in the analyses to index productivity and complexity at the word and sentence level; the total number of words, T-units and clauses, the proportion of correctly spelled words, the MLT-units and clause density in both sentence generation and text production. The macrostructural measure, the number of ideas, was not included in the factor analyses in line with previous work (Arfé et al., 2016). To limit the impact of multi-collinearity, the number of clauses was not included given the strength of relationships with the number of words and T-units. The KMO of 0.55 , being above 0.5 was considered to be acceptable confirming the adequacy of the sample with Bartlett's test of sphericity also significant $\left(x_{(45)}^{2}=386.31, p<0.001\right)$. Four factors emerged with Eigenvalues $>1$. Factor 1 (Eigenvalue $=3.30$ ) explained $32.96 \%$ of the variance with Factor 2 (Eigenvalue $=1.90$ ) accounting for an additional $18.90 \%$, Factor 3 (Eigenvalue $=1.46$ ) a further 14.62\%, and Factor 4 (Eigenvalue $=1.07$ ) an additional $10.71 \%$ of the variance. The loadings of variables on this four factor structure (suppressing loadings below 0.4) is displayed in Table 4. We interpreted Factor 1 as an index of writing productivity, Factor 2 as an index of writing complexity in 
Table 4 Factor loadings for exploratory factor analysis using principal component analysis with varimax extraction of the indices of writing performance

\begin{tabular}{lllll}
\hline Item & $\begin{array}{l}\text { Productivity fac- } \\
\text { tor loading }\end{array}$ & $\begin{array}{l}\text { TP complexity } \\
\text { factor loading }\end{array}$ & $\begin{array}{l}\text { Text spelling fac- } \\
\text { tor loading }\end{array}$ & $\begin{array}{l}\text { SG complex- } \\
\text { ity factor } \\
\text { loading }\end{array}$ \\
\hline TP. number of words & .84 & & & \\
SG. number of words & .81 & & & \\
TP. T-units & .76 & & & \\
SG. T-units & .70 & -.50 & & \\
TP. MLT-units & & .90 & .87 & .85 \\
TP. clause density & & .88 & .85 & .69 \\
SG. \% spelled correct & & & & \\
TP. \% spelled correct & & & & \\
SG. MLT-units & & & & \\
SG. clause density & & & & \\
\hline
\end{tabular}

SG, Sentence Generation; TP, Text Production; MLT-units, Mean Length of T-units

text production, Factor 3 as an index of spelling ability and Factor 4 as an index of writing complexity in sentence generation. This structure follows almost exactly that identified by Arfé et al. (2016) except that the absence of accuracy measures (gender agreement being minimal in English) resulted in a factor of text spelling. Combined, the factors accounted for $77.24 \%$ of the variation in writing performance.

\section{Correlations}

First order correlation coefficients among the socio-economic indices, the HLE scales and book exposure, the language and nonverbal composites and the indices of writing are presented in Table 5. Socio-economic indices bore little relation to the HLE or to the language and nonverbal composite scores. The only exception to this was a relationship between parental qualification and book exposure. We are therefore confident that any effects related to the HLE, language and nonverbal abilities should not be interpreted as merely reflecting the socio-economic status of the children's homes.

There were consistent differences in the relationships between code- and meaning-related experiences and alphabet transcription, word spelling, and the number of ideas produced. Meaning-related experiences, indexed either by the reported frequency of such experiences or book exposure were not associated with these aspects of writing, whereas code-related experiences focusing on letter-sound interactions, although not the frequency of letter activities, were. Thus the categorisation of experiences in the HLE as focused on meaning or code provides traction in understanding the relationship between the HLE and writing skills. Furthermore, significant associations arose primarily at the sub-lexical and lexical levels and not the sentence or text levels. Measures of the productivity and complexity of children's sentences 


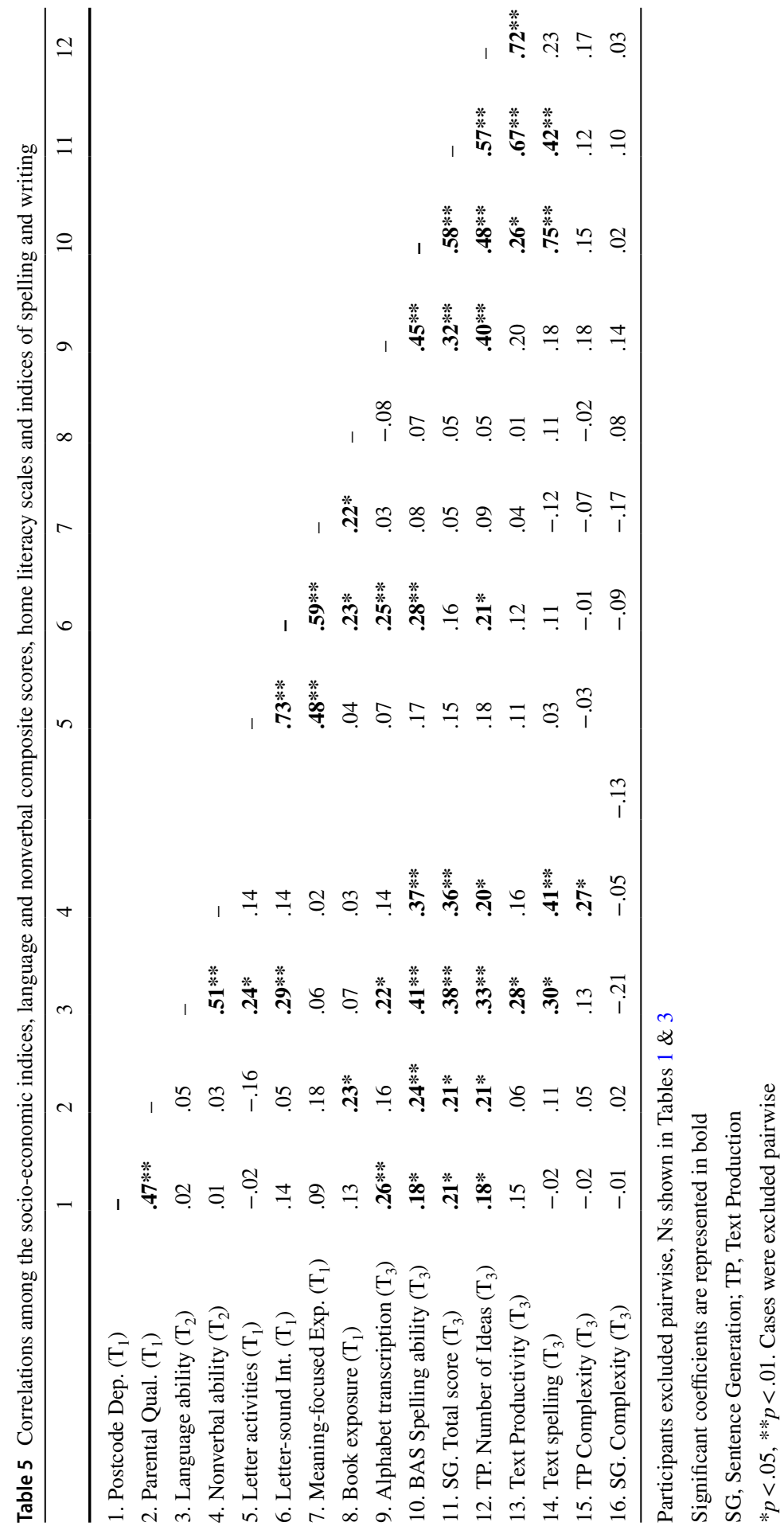


and texts, or their translation skills indexed by sentence generation, were not related to HLE indices. In contrast, indices of the HLE bore significant associations with sub-lexical and lexical transcription skills. The one exception to this pattern was the significant association between the frequency of letter-sound interactions and the number of ideas included in the text.

\section{Multiple regressions}

The only index of the HLE which bore relationships with spelling and writing was the frequency of letter-sound interactions. Evaluation of research question four will therefore be addressed towards just this measure of the HLE.

Hierarchical multiple regressions explored whether letter-sound interactions predicted variation in spelling and writing independently of children's language and nonverbal abilities. Separate regressions were conducted for each of the variables that were associated with letter-sound interactions; alphabet transcription, word spelling, and the number of ideas in the extended texts as the outcome variables. The three predictors were entered into the regression in the order; nonverbal ability, language ability and letter-sound interactions. These regressions are summarised in Table 6.

Together, the preschool measures predicted a significant proportion $(8.6 \%)$ of the variance in alphabet transcription, $F(3,99)=3.104, p=0.03$. Neither language nor nonverbal ability individually were significant predictors. Notably however, when entered at the final step of the regression, the frequency of preschool parent-child interactions around letters and their sounds predicted significant, unique variance $(3.7 \%)$ in alphabet transcription.

Together, all three predictors accounted for a large proportion (23.1\%) of the variance in spelling, $F(3,99)=9.885, p<0.001$. Nonverbal ability $(13.4 \%)$ and language ability (an additional 6.8\%) both made a significant contribution. When entered at

Table 6 Hierarchical regression analyses predicting spelling and writing on the basis of nonverbal ability, language ability and the frequency of letter-sound interactions in the preschool HLE

\begin{tabular}{lllllll}
\hline Predictor & $\mathrm{R}^{2}$ & $\mathrm{R}^{2}$ change & $\mathrm{SE}$ B & $B$ & $\mathrm{~T}$ & $p$ \\
\hline Alphabet transcription & & & & & & \\
Step 1. nonverbal ability & .019 & .019 & .381 & .137 & 1.394 & .166 \\
Step 2. language ability & .049 & .030 & .390 & .200 & 1.766 & .081 \\
Step 3. HLE letter-sound interactions & .086 & .037 & .279 & .202 & 2.014 & .047 \\
Word spelling & & & & & & \\
Step 1. nonverbal ability & .134 & .134 & 4.062 & .366 & 3.948 & $<.001$ \\
Step 2. language ability & .202 & .068 & 4.05 & .303 & 2.917 & .004 \\
Step 3. HLE letter-sound interactions & .231 & .029 & 2.905 & .178 & 1.928 & .057 \\
TP number of ideas & & & & & & \\
Step 1. nonverbal ability & .039 & .039 & .424 & .196 & 1.969 & .045 \\
Step 2. language ability & .113 & .074 & .424 & .313 & 2.792 & .005 \\
Step 3. HLE letter-sound interactions & .115 & .002 & .307 & .128 & 1.279 & .647 \\
\hline
\end{tabular}


the final step of the regression, letter-sound interactions predicted a further $2.9 \%$ of the variance, although this just failed to reach traditional levels of significance $(p=0.057)$.

Together the three predictors explained $11.5 \%$ of the variance in the number of ideas within the texts, $F(3,99)=4.303, p=0.007$. The initial contribution of nonverbal ability $(3.9 \%)$ was significant as was the additional variance contributed by language ability (7.4\%) entered at step 2 . Letter-sound interactions did not explain further significant variance when entered at the final step.

\section{Discussion}

The present study extended our understanding of the relationships between experiences in the preschool HLE and later spelling and writing skills. In response to our first research question, we confirmed that some aspects of children's writing skills at the start of their third year of primary education were related to the frequency of certain home literacy experiences during the preschool period. Although other studies have examined relationships between the HLE and spelling or writing contemporaneously during preschool (Hofslundsengen et al., 2019; Puranik et al., 2018) or longitudinally during the school years (Guo et al., 2020), our study is the first to present evidence of the relationship which spans the preschool to school period.

Our second question focused on the nature of the preschool HLE experiences. Building on the influential distinction established in reading research (Hamilton et al., 2016; Sénéchal et al., 2017), we evaluated the relative importance of codeand meaning-related experiences. Consistent with evidence from reading (Hamilton et al., 2016; Puglisi et al., 2017) and spelling (Hood et al., 2008), differential relationships were identified between spelling and writing and code- and meaningrelated experiences. We identified closer associations with the reported frequency of code-related experiences, specifically parent-child interactions around letters and their sounds, than with meaning-related experiences and the objective measure of parents' familiarity with children's books. By surveying a broader range of coderelated experiences than is typical (e.g., Puglisi et al., 2017; Silinskas et al., 2020), we were able to identify the type of code-related experiences that were most closely related to spelling and writing skills.

Our third research question extended previous research (Hofslundsengen et al., 2019; Puranik et al., 2018) through the systematic exploration of precise features of writing at the sub-lexical, lexical, sentence and text levels, adopting measures which directly reflect processes specified in models of writing. The findings confirmed our prediction that code-related experiences would be more closely related to sublexical and lexical productive literacy skills, but not our prediction that meaningrelated experiences would be related to sentence and text level indices of writing performance. Given previous evidence of direct links between code-related experiences and children's knowledge of grapheme-phoneme correspondence (Martini \& Sénéchal, 2012; Stephenson et al., 2008), we might propose that the association between letter-sound interactions and transcription skills may reflect a role for this aspect of the preschool HLE in supporting understanding of the alphabetic principle 
underpinning the development of transcription skills (McBride-Chang \& Ho., 2005). The absence of a relationship with text spelling may appear to be at odds with this account. However, there is evidence that spelling individual words to dictation may be reliant upon different cognitive processes than those supporting spelling accuracy during text construction (Adams \& Simmons, 2019; Harrison et al., 2016). The lack of a relationship between meaning-related aspects of the HLE and sentence and text level writing was unexpected given associations between such experiences and skills underpinning reading comprehension (Hood et al., 2008; Manolitsis et al., 2013). One explanation may be that for these novice writers, the exigencies of transcription may simply consume cognitive resources to the extent that few remain available to support idea generation or translation processes which enable the refinement of syntactic expression (Berninger \& Winn, 2006; McCutchen, 2000). This account may also explain the relationship between letter-sound interactions and the number of ideas included in the texts, with weaker transcription abilities constraining the quality of writing (Kim et al., 2011), although it should be noted that this association did not withstand controlling for language and nonverbal abilities. The meta-analysis of Kent and Wanzek (2016) confirmed the crucial role of transcription processes in writing development, noting the influence extended throughout the school years. Whether any advantage in transcription skills, associated with a HLE with more frequent parent-child interactions around letters and their sounds, delivers benefits for translational processes later in writing development, including also the investigation of a wider array of more naturalistic writing tasks, should be the focus of future research. This question should be addressed in the light of the diminishing processing capacity demands of transcription and translation skills with increasing writing mastery, as suggested by the not-so-simple view of writing (Berninger \& Swanson, 1994; Berninger \& Winn, 2006).

The close associations between writing development and both oral language and nonverbal skills (Olinghouse \& Leaird, 2008; Salas \& Silvente, 2020), impelled our final research question to determine whether any observed relationships between spelling and writing and the HLE were independent of these aspects. We were able to conclude that the relationships between the frequency of letter-sound interactions and later transcription skills are independent of children's language and nonverbal abilities, certainly in the case of handwriting fluency and possibly in the case of word spelling where the relationship just missed conventional levels of significance.

\section{Limitations and future research directions}

Inconsistencies in the construal and measurement of the HLE (e.g., framing the experience as didactic or more informal exposure and characterising the content as code- or meaning-related) complicates the interpretation of findings and any attempts to address such ambiguities should be welcomed (c.f., Krijnen et al., 2020). Moreover, whilst it may be tempting to conclude that earlier preschool skills have a causal influence on later writing, this interpretation cannot be unambiguously upheld by the current data. Any relationships may be bi-directional with parents 
altering home experiences in accordance with children's skill levels (Inoue et al., 2018; Kim, 2009).

Intervention studies are required to evaluate any causal impact of the HLE on the development of spelling and writing. The current findings suggest that beneficial effects may accompany informal interactions around letters and their sounds which are integrated into everyday activities (e.g., spotting letters in environmental print). Interventions based on such activities may be welcomed more favourably than formal, didactic activities, especially by parents who are less willing or less confident in their abilities to take on a teaching role in the home (Stipek et al., 1992). Careful construction of intervention characteristics would allow direct contrasts to be made. For example, comparing the promotion of meaning- or code-related experiences and contrasting the manner of engagement (e.g., comparing didactic experiences with playful exposure within everyday activities).

\section{Conclusions}

The present findings have important implications for our understanding of the nature of interactions in the preschool home that may be influential in the development of spelling and writing. They raise the possibility that a preschool HLE, rich in parent-child interactions focusing on the code that connects spoken and written language, may be more beneficial for the development of transcription skills than activities centred on letters alone or the extent of their exposure to books and the frequency of literacy experiences focused around meaning. Furthermore, the breadth of HLE activities we assessed suggests that exposure to the codes of written language during everyday activities may be as beneficial as the more didactic code-related experiences highlighted in previous research (Guo et al., 2020; Puranik et al., 2018). Highlighting the potential benefits of integrating informal code-related experiences into pre-schoolers' everyday activities, without a label of teaching, may ultimately enable the more successful promotion of a richer HLE to a broader array of families (DeBaryshe et al., 2000; Weigel et al., 2006).

Supplementary Information The online version contains supplementary material available at. https://doi. org/10.1007/s11145-021-10133-w.

Acknowledgements Our most sincere gratitude is extended to the children, parents, nursery workers and teachers who gave so consistently and enthusiastically of their time whilst participating in this research.

Funding This project was funded by the Nuffield Foundation, but the views expressed are those of the authors and not necessarily those of the Foundation. Grant Reference: EYP/42410.

Availability of data and material The Home Learning Environment Scale is available on request through the Liverpool Early Number Skills Research Team. 


\section{Compliance with ethical standards}

Conflicts of interest The authors declare no conflicts of interest.

Open Access This article is licensed under a Creative Commons Attribution 4.0 International License, which permits use, sharing, adaptation, distribution and reproduction in any medium or format, as long as you give appropriate credit to the original author(s) and the source, provide a link to the Creative Commons licence, and indicate if changes were made. The images or other third party material in this article are included in the article's Creative Commons licence, unless indicated otherwise in a credit line to the material. If material is not included in the article's Creative Commons licence and your intended use is not permitted by statutory regulation or exceeds the permitted use, you will need to obtain permission directly from the copyright holder. To view a copy of this licence, visit http://creativecommons.org/licen ses/by/4.0/.

\section{References}

Adams, A.-M., \& Simmons, F. (2019). Exploring individual and gender differences in early writing performance. Reading and Writing: An Interdisciplinary Journal, 32, 235-263. https://doi.org/10.1007/ s11145-018-9859-0

Adams, A.-M., Simmons, F., \& Willis, C. (2015). Exploring relationships between working memory and writing: individual differences associated with gender. Learning and Individual Differences, 40, 101-107. https://doi.org/10.1016/j.lindif.2015.04.011

Aram, D., Korat, O., \& Hassunah-Arafatet, S. (2013). The contribution of early home literacy activities to first grade reading and writing achievements in Arabic. Reading and Writing: An Interdisciplinary Journal, 26, 1517-1536. https://doi.org/10.1007/s11145-013-9430-y

Aram, D., \& Levin, I. (2001). Mother-child joint writing in low SES: sociocultural factors, maternal mediation and emergent literacy. Cognitive Development, 16, 831-852.

Arfé, B., Dockrell, J., \& De Bernardi, B. (2016). The effect of language specific factors on early written composition: the role of spelling, oral language and text generation skills in a shallow orthography. Reading and Writing: An Interdisciplinary Journal, 29, 501-527.

Berninger, V. W. \& Swanson, H. L. (1994). Modifying Hayes and Flower's model of skilled writing to explain beginning and developing writing. In: E. C. Butterfield (Ed.), Children's writing: Toward a process theory of the development of skilled writing. JAI Press, Greenwich.

Berninger, V. W., \& Winn, W. (2006). Implications of advancements in brain research and technology for writing development, writing instruction, and educational evolution. In C. A. MacArthur, S. Graham, \& J. Fitzgerald (Eds.), Handbook of writing research (pp. 96-114). Guilford Press.

Berninger, V., Yates, C., Cartwright, A., Rutberg, J., Remy, E., \& Abbott, R. (1992). Lower-level developmental skills in beginning writing. Reading and Writing: An Interdisciplinary Journal, 4(3), 257280. https://doi.org/10.1007/bf01027151

De Jong, P. F., \& Leseman, P. M. (2001). Lasting effects of home literacy on reading achievement in school. Journal of School Psychology, 39(5), 389-414.

DeBaryshe, B. D., Binder, J. C., \& Buell, M. J. (2000). Mothers' implicit theories of early literacy instruction: Implications for children's reading and writing. Early Child Development and Care, 160(1), 119-131. https://doi.org/10.1080/0030443001600111

Dockrell, J. E., Connelly, V., \& Arfé, B. (2019). Struggling writers in elementary school: capturing drivers of performance. Learning and Instruction, 60, 75-84.

Dodd, B., Crosbie, S., MacIntosh, B., Teitzel, T., \& Ozanne, A. (2000). Preschool and primary inventory of phonological awareness (PIPA). Psychological Corporation.

Drijbooms, E., Groen, M. A., \& Verhoeven, L. (2015). The contribution of executive functions to narrative writing in fourth grade children. Reading and Writing: An Interdisciplinary Journal, 28, 9891011. https://doi.org/10.1007/s11145-015-9558-z

Drouin, M., \& Harmon, J. (2009). Name writing and letter knowledge in preschoolers: incongruities in skills and the usefulness of name writing as a developmental indicator. Early Childhood Research Quarterly, 24, 263-270.

Elliot, C. D., \& Smith, P. (2011). British Ability Scales-Third Edition (BAS-3). GL Assessment. 
Gerde, H. K., Skibbe, L. E., Bowles, R. P., \& Martoccio, T. L. (2012). Child and home predictors of children's name writing. Child Development Research. https://doi.org/10.1155/2012/748532

Gough, P. B., \& Tunmer, W. E. (1986). Decoding, reading and reading disability. Remedial and Special Education, 7, 6-10.

Guo, Y., Puranik, C., Kelcey, C., Sun, J., Schneider Dinnesen, M., \& Breit-Smith, A. (2020). The role of home literacy practices in kindergarten children's early writing development: a one-year longitudinal study. Early Education and Development. https://doi.org/10.1080/10409289.2020.1746618

Hamilton, L. G., Hayiou-Thomas, M. E., Hulme, C., \& Snowling, M. J. (2016). The home literacy environment as a predictor of the early literacy development of children at family-risk of dyslexia. Scientific Studies of Reading, 20(5), 401-419. https://doi.org/10.1080/10888438.2016.1213266

Harrison, G. L., Goegan, L. D., Jalbert, R., McManus, K., Sinclair, K., \& Spurling, J. (2016). Predictors of spelling and writing skills in first-and second-language learners. Reading and Writing: An Interdisciplinary Journal, 29(1), 69-89. https://doi.org/10.1007/s11145-015-9580-1

Hofslundsengen, H., Gustafsson, J.-E., \& Eriksen-Hagtvet, B. (2019). Contributions of the home literacy environment and underlying language skills to preschool invented writing. Scandinavian Journal of Educational Research, 63(5), 653-669. https://doi.org/10.1080/00313831.2017.1420686

Hood, M., Conlon, E., \& Andrews, G. (2008). Preschool home literacy practices and children's literacy development: a longitudinal analysis. Journal of Educational Psychology, 100(2), 252. https://doi.org/ 10.1037/0022-0663.100.2.252

Hooper, S. R., Swartz, C. W., Wakely, M. B., de Kruif, R. E., \& Montgomery, J. W. (2002). Executive functions in elementary school children with and without problems in written expression. Journal of Learning Disabilities, 35(1), 57-68. https://doi.org/10.1177/002221940203500105

Hunt, K. W. (1965). Grammatical structure written at three grade levels (p. 3). National Council of Teachers of English, Research Report No.

Inoue, T., Georgiou, G. K., Muroya, N., Maekawa, H., \& Parrila, R. (2018). Can earlier literacy skills have a negative impact on future home literacy activities? Evidence from Japanese. Journal of Research in Reading, 41, 159-175. https://doi.org/10.1111/1467-9817.12109

Juel, C. (1988). Learning to read and write: A longitudinal study of 54 children from 1st through 4th grades. Journal of Educational Psychology, 80(4), 437-447. https://doi.org/10.1037/0022-0663.80.4.437

Kent, S. C., \& Wanzek, J. (2016). The relationship between component skills and writing quality and production across developmental levels: a meta-analysis of the last 25 years. Review of Educational Research, 86(2), 570-601.

Kent, S., Wanzek, J., Petscher, Y., Al, O. S., \& Kim, Y.-S. (2014). Writing fluency and quality in kindergarten and first grade: the role of attention, reading transcription and oral language. Reading and Writing: An Interdisciplinary Journal, 27(7), 1163-1188. https://doi.org/10.1044/1092-4388

Kim, Y.-S. (2009). The relationship between home literacy practices and developmental trajectories of emergent literacy and conventional literacy skills for Korean children. Reading and Writing: An Interdisciplinary Journal, 22, 57-84. https://doi.org/10.1007/s11145-007-9103-9

Kim, Y.-S., AlOtaiba, S., Folsom, J. S., Greulich, L., \& Puranik, C. (2014). Evaluating the dimensionality of first-grade written composition. Journal of Speech, Language, and Hearing Research, 57(1), 199-211. https://doi.org/10.1044/1092-4388(2014/12-01.52

Kim, Y.-S., AlOtaiba, S., Puranik, C., Folsom, J. S., Greulich, L., \& Wagner, R. K. (2011). Componential skills of beginning writing: an exploratory study. Learning and Individual Differences, 21(5), 517-525. https://doi.org/10.1016/j.lindf.2011.06.004

Kim, Y.-S., AlOtaiba, S., Wanzek, J., \& Gatlin, B. (2015). Toward an understanding of dimensions, predictors, and the gender gap in written composition. Journal of Educational Psychology, 107(1), 79. https:// doi.org/10.1037/a0037210

Kochanska, G., Murray, K. T., \& Harlan, E. T. (2000). Effortful control in early childhood: Continuity and change, antecedents, and implications for social development. Developmental Psychology, 36(2), 220232. https://doi.org/10.1037/0012-1649.36.2.220

Krijnen, E., Van Steensel, R., Meeuwisse, M., Jongerling, J., \& Severiens, S. (2020). Exploring a refined model of home literacy activities and associations with children's emergent literacy skills. Reading and Writing: An Interdisciplinary Journal, 33(1), 207-238. https://doi.org/10.1007/s11145-019-09957-4

Mackie, C. J., Dockrell, J., \& Lindsay, G. (2013). An evaluation of the written texts of children with SLI: The contribution of oral language, reading and phonological short-term memory. Reading and Writing: An Interdisciplinary Journal, 26(6), 865-888. https://doi.org/10.1007/s11145-012-9396-1

Manolitsis, G., Georgiou, G. K., \& Tziraki, N. (2013). Examining the effects of home literacy and numeracy environment on early reading and math acquisition. Early Childhood Research Quarterly, 28, 692-703. 
Martini, F., \& Sénéchal, M. (2012). Learning literacy skills at home: parent teaching, expectations, and child interest. Canadian Journal of Behavioural Science/Revue Canadienne des Sciences du Comportement, 44(3), 210. https://doi.org/10.1037/a0026758

McBride-Chang, C., \& Ho, C. S. (2005). Predictors of beginning reading in Chinese and English: A 2-year longitudinal study of Chinese kindergartners. Scientific Studies of Reading, 9, 117-144. https://doi.org/ 10.1207/s1532799xssr0902

McCutchen, D. (2000). Knowledge, processing, and working memory: implications for a theory of writing. Educational Psychologist, 35(1), 13-23. https://doi.org/10.1207/S1532698EP3501_3

Niklas, F., \& Schneider, W. (2017). Intervention in the home literacy environment and kindergarten children's vocabulary and phonological awareness. Reading and Writing: An Interdisciplinary Journal, 33, 877-905. https://doi.org/10.1007/s11145-019-09979-y

Olinghouse, N. G., \& Leaird, J. T. (2008). The relationship between measures of vocabulary and narrative writing quality in second and fourth-grade students. Reading and Writing: An Interdisciplinary Journal, 22, 545-565. https://doi.org/10.1007/s11145-008-9124-z

Puglisi, M. L., Hulme, C., Hamilton, L. G., \& Snowling, M. J. (2017). The home literacy environment is a correlate, but perhaps not a cause, of variations in children's language and literacy development. Scientific Studies of Reading, 21(6), 498-514. https://doi.org/10.1080/10888438.2017.1346660

Puranik, C. S., Lombardino, L. J., \& Altmann, L. J. P. (2008). Assessing the microstructure of written language using a retelling paradigm. American Journal of Speech-Language Pathology, 17(2), 107-120.

Puranik, C., \& Lonigan, C. (2012). Name-writing proficiency, not length of name, is associated with preschool children's emergent literacy skills. Early Childhood Research Quarterly, 27(2), 284-294.

Puranik, C., Phillips, B. M., Lonigan, C., \& Gibson, E. (2018). Home literacy practices and preschool children's emergent writing skills: an initial investigation. Early Childhood Research Quarterly, 42, $228-238$.

Salas, N., \& Silvente, S. (2020). The role of executive functions and transcription skills in writing: a crosssectional study across 7 years of schooling. Reading and Writing: An Interdisciplinary Journal, 33, 877-905. https://doi.org/10.1007/s11145-019-09979-y

Sénéchal, M. (2006). Testing the home literacy model: parent involvement in kindergarten is differentially related to grade 4 reading comprehension, fluency, spelling, and reading for pleasure. Scientific Studies of Reading, 10(1), 59-87. https://doi.org/10.1207/s1532799xssr1001_4

Sénéchal, M., \& LeFevre, J.-A. (2002). Parental involvement in the development of children's reading skill: a five-year longitudinal study. Child Development, 73(2), 445-460. https://doi.org/10.1111/1467-8624. 00417

Sénéchal, M., LeFevre, J.-A., Thomas, E. M., \& Daley, K. E. (1998). Differential effects of home literacy experiences on the development of oral and written language. Reading Research Quarterly, 33(1), 96-116.

Sénéchal, M., Whissell, J., \& Bildfell, A. (2017). Starting from home: home literacy practices that make a difference. In: K. Cain, D. L. Compton, \& R. K. Parrila (Eds.) Theories of reading development. Doi:https://doi.org/10.1075/swll.15.22sen

Silinskas, G., Torppa, M., Lerkkanen, M. K., \& Nurmi, J. E. (2020). The home literacy model in a highly transparent orthography. School Effectiveness and School Improvement, 31(1), 80-101. https://doi.org/ 10.1080/09243453.2019.1642213

Skwarchuk, S. L., Sowinski, C., \& LeFevre, J.-A. (2014). Formal and informal home learning activities in relation to children's early numeracy and literacy skills: the development of a home numeracy model. Journal of Experimental Child Psychology, 121, 63-84. https://doi.org/10.1016/j.jecp.2013.11.006

Soto-Calvo, E., Simmons, F. R., Adams, A., Francis, H. N., \& Giofrè, D. (2020a). Pre-schoolers home numeracy and home literacy experiences and their relationships with early number skills: evidence from a UK study. Early Education and Development, 31, 113-136. https://doi.org/10.1080/10409289. 2019.1617012.

Soto-Calvo, E., Simmons, F., Adams, A., Francis, H., Patel, H., \& Giofrè, D. (2020b). Identifying the preschool home learning experiences that predict early number skills: evidence from a longitudinal study. Early Childhood Research Quarterly, 53, 314-328. https://doi.org/10.1016/j.ecresq.2020.04.004.

Stephenson, K. A., Parrila, R. K., Georgiou, G. K., \& Kirby, J. R. (2008). Effects of home literacy, parents' beliefs, and children's task-focused behavior on emergent literacy and word reading skills. Scientific Studies of Reading, 12(1), 24-50. https://doi.org/10.1080/10888430701746864

Stipek, D., Milburn, S., Clements, D., \& Daniels, D. H. (1992). Parents' beliefs about appropriate education for young children. Journal of Applied Developmental Psychology, 13, 293-310. 
Treiman, R., Hulslander, J., Olson, R. K., Willcutt, E. G., Byrne, B., \& Kessler, B. (2019). The unique role of early spelling in the prediction of later literacy performance. Scientific Studies of Reading, 23(5), 437-444. https://doi.org/10.1080/10888438.2019.1573242

Wagner, R. K., Puranik, C., Foorman, B., Foster, E., Wilson, L. G., Tschinkel, E., \& Kantor, P. T. (2011). Modeling the development of written language. Reading and Writing: An Interdisciplinary Journal, 24(2), 203-220. https://doi.org/10.1007/s11145-010-9266-7

Wechsler, D. (2005). Wechsler Individual Acheivement Test. The Psychological Corporation.

Wechsler, D. (2013). Wechsler Preschool and Primary Scale of Intelligence-Fourth UK Edition (WPPSI-IV $U K)$. Pearson Education.

Weigel, D. J., Martin, S. S., \& Bennett, K. K. (2006). Contributions of the home literacy environment to preschool-aged children's emerging literacy and language skills. Early Child Development and Care, 176(3 \& 4), 357-378. https://doi.org/10.1080/03004430500063747

Whitehurst, G., \& Lonigan, C. (1998). Child development and emergent literacy. Child Development, 69(3), 848-872.

Wiebe, S. A., Sheffield, T. D., \& Espy, K. A. (2012). Separating the fish from the sharks: a longitudinal study of preschool response inhibitory control. Child Development, 83(4), 1245-1261. https://doi. org/10.1111/j.1467-8624.2012.01765.x

Publisher's Note Springer Nature remains neutral with regard to jurisdictional claims in published maps and institutional affiliations. 